\title{
Mobile and Web-Based Support in Overcoming Behavioral Difficulties of Adolescents
}

\author{
https://doi.org/10.3991/ijet.v16i04.18577 \\ Gulmira Kassen ${ }^{\bowtie}$, Aliya Kudaibergenova, Anar Mukasheva, \\ Dinara Yertargynkyzy, Kuanysh Moldassan \\ Kazakh National University Al-Farabi, Almaty, Kazakhstan \\ gulmira.kassen@mail.ru
}

\begin{abstract}
A significant proportion of adolescents and young adults experience behavioral difficalties as they grow up. Minor disorders without control and relief can cause significant psychological problems and disorders or form dangerous life paths for a teenager. Mobile devices and applications have been actively used for over a decade to monitor and provide psychological assistance to adolescents. The aim of this study was to identify the level of effectiveness of the impact of mobile and online support for adolescents on the assessment of changes in problem behavior and psychological state of adolescents. The study involved 672 adolescents aged 13 to 15 years from one of the schools in Almaty (Kazakhstan). The participants were divided into three groups, one of which received online and mobile regular psychological support and information, the second, the support group, received support in face-to-face communication with teachers, parents and psychologists, and the third, the control group, received support only upon request from the teenager. or his parents. According to the results of the study, a survey was conducted on the Likert scale, in which adolescents, parents and teachers assessed the level of behavioral changes associated with the condition and behavior difficulties. In the experimental group, the assessment of behavioral changes reached a maximum of 4.028 on a 5-point scale of positive changes, while the other two groups lagged significantly (2.402 for the support group and 2.12 for the control group). The practical significance of the study lies in the possibility of effective implementation of a support system for adolescents at school based on existing mobile devices and instant messengers without significant costs.
\end{abstract}

Keywords-Problem behavior, mobile support, online support, adolescent psychology

\section{Introduction}

The so-called behavior difficulties of adolescents has been the subject of research in psychology and pedagogy for a very long time [1-3]. Problem behavior does not have a clear, unambiguously recognized definition, but most studies recognize it as such in the case when a teenager violates the rules of social behavior, social norms of behavior accepted in his environment, shows increased aggression or nervousness [4]. 
Many researchers also classify groups of symptoms of some mental disorders as behavior difficulties. At the same time, such symptoms do not require medication or restriction of the freedom of a young adult, establishing control over him. As a result of awareness, psychological changes, and growing up, these behavior difficulties often go away without additional intervention. However, one cannot simply ignore the presence of such behavior difficulties in anticipation of growing up and age-related psychological changes. As various researchers point out, without relief, such problematic forms of behavior can stabilize, become habits, lead to antisocial behavior, criminogenic choice of actions, and drug use. Behavior difficulties is the realization of a latent need for deeper psychological contact and deeper relationships with parents and mentors, obtaining a socially conditioned place among peers, recognition in the environment of a young adult [5]. Based on this, to stop problematic forms of behavior requires external intervention in the form of psychological assistance. Such assistance can take various forms, among which may be behavioral counseling, psychotherapeutic assistance, moral support and motivation, provision of necessary information and access to training sources [6].

The use of mobile apps and mobile devices to help teenagers has also been researched for about a decade. In most cases, special applications or mobile services are now offered, aimed both at teaching a teenager to certain types of behavior, and at developing the ability to solve real-life problems. Applications use various psychological stimuli, images and themes that are close to adolescents to influence with the help of mobile gaming content [7,8]. The implementation of such applications is often costly and cannot always be correctly assessed in terms of effectiveness and control by psychologists and educators. At the same time, the impact of mobile specialized services and applications in parallel with the work of practical psychologists, social workers and parents gives noticeable statistically reliable positive results in stopping problem behavior [9].

Behavior difficulties may not have manifestations that would be recorded by the majority of others, as in the case of aggressive behavior or self-destructive behavior. Early recognition of such situations is especially important to prevent more complex behavioral disorders in adolescents or young people of college age [10]. Mobile applications as well as specialized mobile devices are successfully used for both medical and psychological monitoring and prevention of excessive conditions. The opportunity to receive regular help and support in itself eliminates most of the excesses and helps stabilize the personality of a teenager or young person who has manifestations of behavior difficulties [4].

Disorders can be inactivity, loss of interest in ordinary employment or learning, lack of pronounced life goals, plans or desires, lack of friends and full-fledged connections and communication in a team, depression, etc. [9]. Some researchers are inclined to believe that different types of behavioral disorders in adolescents are not generally related to each other and are separate phenomena. For example, the absence of social connections can gradually be supplemented by the absence of clearly expressed goals or manifestations of aggression, depressive states, or it may not lead to their appearance. Research in this area is ongoing [11]. At the same time, some researchers draw attention to the fact that the accumulation of behavior difficulties 
can have a gross effect, increasing the danger for the adequate development of the personality of a teenager and his further life path [11].

The objective of this study is to establish the possibility of an effective relatively short-term positive impact of mobile and online support of adolescents with behavior difficulties and to develop recommendations regarding the effectiveness of such support. The novelty of the study lies in the use of instant messengers and the simplest available form of counseling for adolescents, rather than specialized mobile applications, to significantly increase the relief of behavior difficulties. The hypothesis of the study is the assumption that the use of mobile and online support based on communication, providing advice and information, and behavioral counseling can significantly reduce the manifestations of behavior difficulties in adolescents and help improve their psychological state.

\subsection{Literature overview}

There is research on mobile counseling and the use of mobile communications and instant messengers to address behavior difficulties in advance. However, in these works, as a rule, it is assumed that adolescents suffering from some forms of behavior difficulties communicate with each other and with their parents [12,13]. It has been observed that the use of text messaging and real-time messaging helps to get out of difficult situations, maintain good relationships and improve the quality of learning $[14,15]$.

On the other hand, the constant use of mobile devices by adolescents and dependence on the Internet has become one of the most researched topics in recent years $[7,16]$. The negative impact of mobile devices, as the most accessible, is manifested in a drop in academic results, a decrease in cognitive abilities, a decrease in the circle of contacts and asociality, and the movement of most of the communication to the Network [17,18]. Also, researchers point to the criminogenic vulnerability of adolescents who communicate on the Internet and attempts to influence them with criminal intent [19].

Mobile applications are increasingly being used in school and college education, mobile technologies are being adapted for online and mobile learning. The digital environment has become part of the natural environment of young adults. Mobile technologies can be of great benefit if they are reoriented in the daily use of adolescents towards the center of support, information and communication. Now, most adolescents in developed countries perceive mobile devices as an entertainment center, which is also associated with a number of behavioral disorders, for example, manifestations of mobile bullying or harassment among adolescents [20,21].

Research on behavior difficulties so far has not overlapped with research on the use of mobile applications for their relief. In most cases, problem behavior is studied to determine its origin or the impact on it of certain psychological methods of influence [19]. Behavior difficulties in adolescents are defined as behavioral patterns that arise from impaired socialization and that are predictors of more complex and dangerous psychological disorders and even crime [22,23]. 


\section{$2 \quad$ Method}

\subsection{Participants}

The study was conducted among students of one of the secondary schools in Almaty (Kazakhstan). For the study, three groups of adolescents aged 13 - 15 years with fixed behavior difficulties were selected. The composition of the participants within the groups is presented in Table 1. The experimental group received support and support for two months with the help of constant contact help of web applications, cloud services and mobile control. The second group received counseling from specialists - psychologists and supervision at school from school psychologists but did not have permanent mobile and web support. For the third group, the participants were provided consultations only in the case of a direct appeal from adolescents themselves, teachers or parents. The third group was considered control in relation to the experimental conditions. The study tested the hypothesis that the presence of constant web-based and mobile support for adolescents with behavior difficulties, the state of anxiety, aggression will decrease, and the number of recorded forms of problematic behavior will decrease over the observation period.

Table 1. The distribution of the participants in the experiment by gender and age.

\begin{tabular}{|l|c|c|c|c|}
\hline & Experimental Group & Supported Group & Control Group & Total \\
\hline Male & 112 & 112 & 115 & 339 \\
\hline Female & 110 & 111 & 112 & 333 \\
\hline Age 13 & 225 & 225 & 222 & 672 \\
\hline Age 14 & 218 & 236 & 218 & 672 \\
\hline Age 15 & 220 & 228 & 224 & 672 \\
\hline
\end{tabular}

All forms of messengers popular among teenagers in this group were used in the form of mobile and web support: Google Hangouts, Facebook Messenger, Viber, What's Up? Adolescents could leave their diaries or questions in the Google Drive "cloud service" for psychologists, and they could also call during working hours and at certain hours of weekends to ask a question. The response to the appeal should have appeared no later than within 10 minutes. Also, simple visual information materials were offered, adapted for the screen of a smartphone or tablet, with explanations of the most common problems in communicating with peers or adults: bullying, the formation of bad habits, street violence, misunderstanding in communication with parents, fatigue at school and others.

After two months of the study, the participants were asked to rate the results of psychological support and counseling over the past period on a Likert scale from 1 to 5, where 5 - "complete improvement in behavior, the participant believes that he no longer has problem behavior", 0 - "everything remains on - still nothing has changed. " They also asked to rate the level of aggression and the level of anxiety as the most important components of behavior difficulties. The subjective assessment of the changes that occurred with adolescents was measured from the point of view of the three groups listed above: adolescents, parents and teachers. The higher the 
assessment of the level of changes in anxiety and aggression, the higher the respondents feel from the point of view of the respondents, the more their well-being improved, the anxiety and aggression decreased. When measuring behavior difficulties, the higher the score, the less difficult the adolescents' behavior appears from the perspective of the respondents. The marks were given by three groups of participants: teenagers, their parents or educators, and also teachers (class teachers). In relation to each participant - a teenager, three estimates were obtained in this way.

\subsection{Ethical issues}

All participants were invited to participate in the study on condition of anonymity and with the permission of parents and teachers. No personal data of the participants was collected or further used. In the course of the study, each of the participants received their own unique identifier, under which all the data that related to this participant was stored, but not his personal data. Thus, the confidentiality of the study was ensured.

\subsection{Statistical processing}

Processing and visualization of statistical data was carried out using the Microsoft Excel software package. In the course of the study, the value of the average mark for each question was determined and the standard deviation was determined.

\section{$2.4 \quad$ Research limitations}

The study covers adolescents from only one country with its specific conditions, and although it is quite representative of the region, its findings should be extended to other regions with caution. The study also does not focus on possible differences in the assessment of relatively small differences in participants by age or gender. Research in this direction can be continued and expanded in the future.

Also a limitation of the study is the insignificant time of its conduct. The behavioral characteristics of adolescents could have changed significantly over a longer period, both in the presence of mobile and online support, and in the event of its termination. The long-term effects of such support require independent research.

\section{Results}

In all the surveys, there was no significant statistical discrepancy between the level of the average assessment of the subgroups of the respondents within one survey and one group. This may indicate a high degree of reliability of the answers and a high degree of correspondence of the subjective assessment of different subgroups, adults and adolescents, to real changes in the behavior of research participants.

Evaluation of the results of the survey on the impact of mobile and online support on anxiety as an important aspect of the formation of behavior difficulties shows a 
homogeneous level in all three subgroups of respondents. The differences in assessment between all three groups turn out to be cardinal and are noticeable even graphically. The level of assessment of changes by the control group is the lowest (1.111 - 1.256), which indicates that adolescents themselves, teachers and parents are confident that the changes have occurred minimal. The highest scores were given by participants in the experimental group who received mobile and web support (4.04 3.892). The assessments of all three subgroups of the respondents coincide within the limits of the statistical error and the standard deviation of the research results. All groups estimate the level of changes as practically the highest. The coincidence of assessments indicates a greater level of adequacy and proximity of the subjective assessment to the real state of affairs.

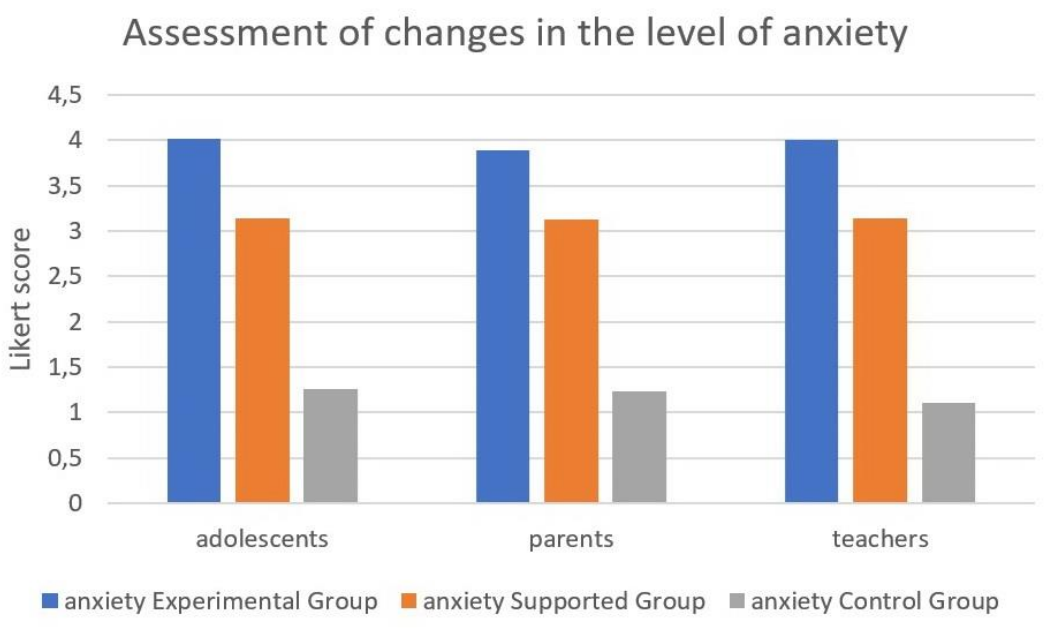

Fig. 1. Assessment of changes in the level of anxiety.

Figure 2 shows the results of assessing the quality of changes in manifestations of aggressiveness as an important component of behavior difficulties. The scores also coincide within the subgroups within the limits of statistical error, and the relationships between the results obtained correspond to those obtained when evaluating changes in the feeling of anxiety. The highest results were demonstrated by the experimental group with almost maximum scores $(4.235-4.028)$, and the lowest results by the control group $(2.141-2.12)$. As in the case of the study of changes in the feeling of anxiety, the indicators of the support group (the second group) are approximately halfway between the extreme indicators of the other two groups.

Perhaps the reason for this situation is that for adolescents with problematic elements of behavior, the most significant factor in changing for the better and stabilizing behavior is the availability of regular and most accessible support on an ongoing basis. 


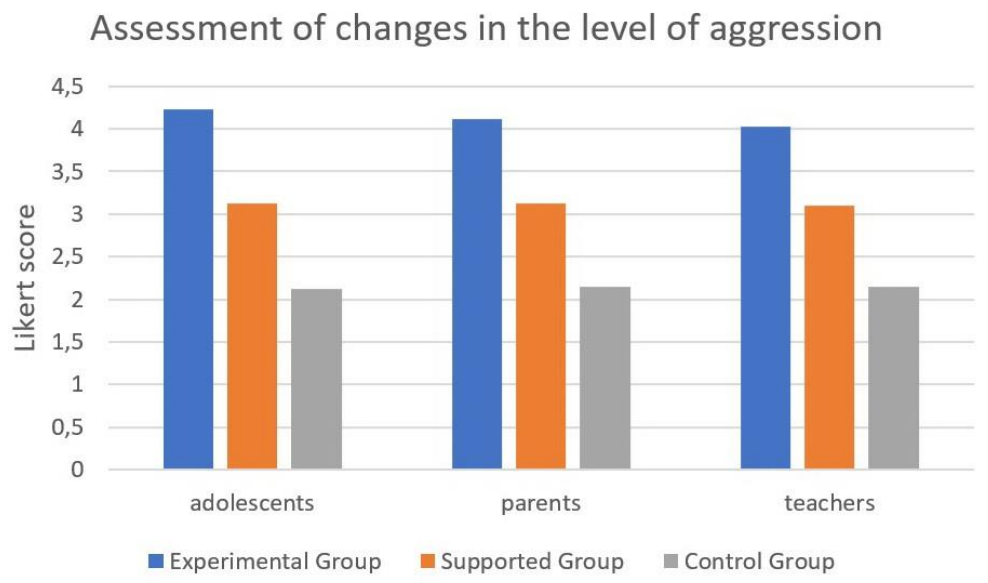

Fig. 2. Assessment of changes in the level of aggression.

Evaluating visible changes in behavior difficulties is especially important as it concerns those behaviors that are easiest to assess and categorize. The coincidence of the overall values of the assessment in this survey may indicate that the assessment of the factors of aggression and anxiety was also close to reality. Figure 3 shows that the estimates in the experimental group remained the same high, while the estimates of the other two groups approached in their values, although they did not coincide. The assessment of positive behavioral changes by parents, teachers and adolescents themselves in the experimental group is equally high and is. The difference in the assessment of subgroups is within the statistical error. Estimates of changes in behavior difficulties for the experimental group are in the range of 4.028 - 3.881, their extreme line is slightly lower than in the two previous cases (in Figs 1 and 2). The values for the support group are in the range of $2.402-2.221$, and the values for the control group are in the range of 2.12 - 2.01. It should be noted that the indicators of the support group and the control group have independent statistical significance, their average results, taking into account the standard deviation, do not overlap. This suggests that in a support group in which adolescents received regular support, supervision and interviews with psychologists and teachers, the results were generally statistically significantly higher than in a group where help was provided only at the request of parents or adolescents. 


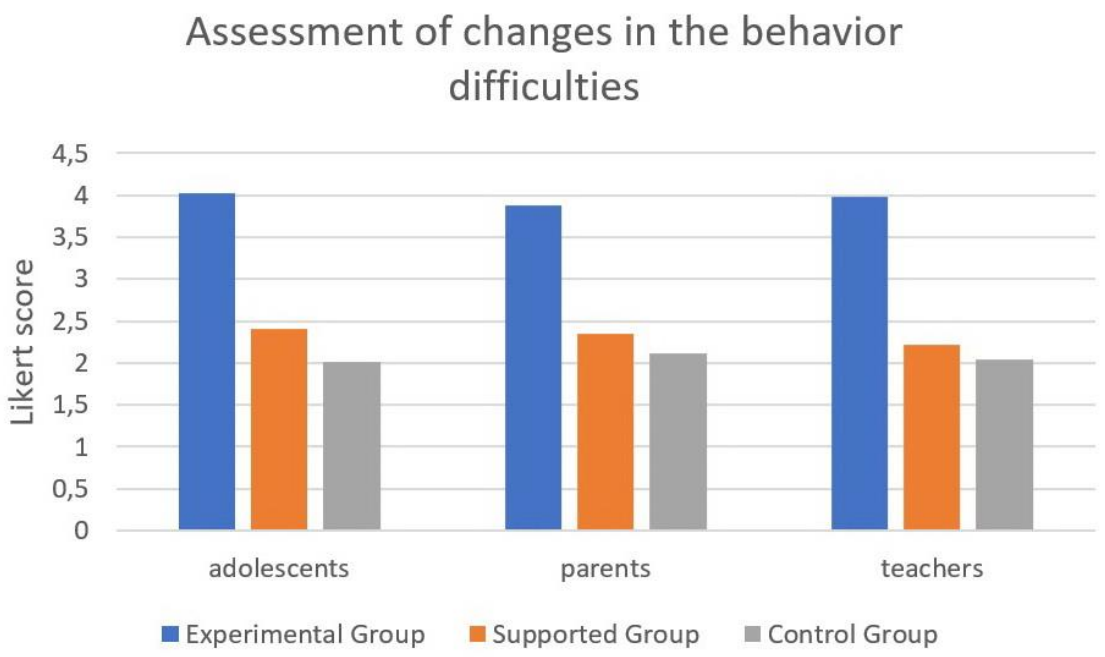

Fig. 3. Assessment of changes in the level of behavior difficulties.

The results of the conducted surveys show that the hypothesis of the research is generally proven. The results of assessing behavioral changes, well-being and visual assessment of the external attributes of the emotional life of adolescents who received mobile-based and web-based psychological regular support were significantly higher than those who received the usual face-to-face support from parents and psychologists, as well as those who received support on request only.

From the observed results of the study, one can draw two conclusions that are very significant for the further development of the system of psychological assistance to adolescents at school. The first finding is that the best results are obtained by having a constant channel of communication and receiving psychological help, emotional support and behavioral advice. Today, such a source is most effectively provided by mobile devices and the help and information system based on "cloud" network services. For the effective implementation of such assistance, it is not necessary to use the constant watch of psychologists or other specialists due to the ability to provide specially prepared materials. If adolescents know that they will definitely receive support and answers to their questions, this already largely removes anxiety and other symptoms of future behavior difficulties.

The second important conclusion is that adolescents and young adults need targeted assistance, which should come without a request in the form of an offer from adults, parents, teachers, psychologists, etc. In most cases, adolescents are reluctant to voice their concerns or deal with them. Therefore, the level of positive change in the group in which assistance was provided only on request was minimal or practically absent.

From a practical point of view, the authors of the study can recommend using the capabilities of mobile communications and online services to dramatically improve the quality of assistance to schoolchildren in solving situations of behavior 
difficulties. Prior counseling in difficult behavioral cases can proactively prevent the occurrence of behavior difficulties. This is possible in cases where the teenager does not have good behavioral choices or does not know how to make them. The organization of basic psychological support does not require the use of special or costly mobile solutions and can be organized with a minimum investment of time and money.

\section{Discussion}

The results obtained as a result of our study in many respects overlap with studies on the use of mobile applications and specialized mobile devices for monitoring the state of various diseases and the psychological state of patients [24]. In the conditions of constant proximity of a multifunctional electronic device to the human body, it becomes possible to measure many parameters of the body, as well as monitor physiological changes that can be predictors of stress or unwanted emotional states. It is especially important to carry out such control in relation to adolescents, whose emotional life is more intense than that of adults and the psychosomatic influence of emotions on the physiological state is stronger [25,26].

Research on behavior difficulties in adolescents also indicates the possibility of effective relief of such disorders using special applications or through a certain type of contact with friends and family [27]. On the other hand, the speed of access to psychological help with the help of mobile devices was considered earlier, but rarely in the context of helping teenagers. Scientists often proceeded from the fact that adolescents most of the time are under the care and supervision of either teachers or parents, therefore psychological assistance is largely the responsibility of these categories of persons [28]. The ever deeper penetration of the digital environment in particular, and into human family relations, leads to the fact that the online and mobile life of adolescents is rarely completely controllable and can itself provoke negative behavioral changes [29]. Therefore, our study focused on the use of mobile and online platforms precisely as a means of exchanging psychotherapeutic information and as a means of communication for receiving psychological help.

Impact on adolescents is often associated with vivid and engaging communicative information, especially from areas of interest [30,31]. On this basis, methods of attracting attention or correcting the behavior of adolescents are created. However, today there is no reliable and unambiguous information that would allow us to believe that exposure using specialized applications, especially gaming, is really effective for stopping behavior difficulties [13].

Numerous works devoted to the study of the use of mobile platforms for maintaining psychological health consider them in most cases as a way of contact of a doctor or professional psychologist with a patient in a limited context or with the help of special applications that streamline such therapeutic communication [29]. In most cases, as follows from our study, adolescents are not inclined to seek help on their own, therefore, the lack of constant and stable contacts and trust in the communication process dramatically reduces the effectiveness of such a process. and 
working with a teenager in a behavioral counseling mode, rather than "problem solving"; in this case, the teenager does not perceive his condition and actions as a problem and acts more flexible and receptive. This kind of communication mode is more consistent with the exchange of text messages, which are popular among the little girls as a certain type of fashionable communication [25].

\section{Conclusion}

The use of mobile devices and online services for psychometrics, psychological monitoring and support of adolescents is being researched all over the world. Digital penetration can bring both negative and positive results in maintaining the psychological health and academic performance of young adults. Mobile devices and applications have been actively used for over a decade to provide psychological assistance to adolescents. This study was carried out in order to establish the level of effectiveness of the impact of mobile and online support for adolescents on the assessment of changes in behavior difficulties and psychological state of adolescents. The study involved 672 adolescents aged 13 to 15 years (Almaty, Kazakhstan). The participants made up three separate groups, one of them received regular online and mobile psychological support and information, the second, the support group, received support in face-to-face communication with teachers, parents and psychologists, and the third, the control group, received support only upon request from the adolescent or their parents. The results of the study on the base of Likert scale demonstrate evaluation of adolescents themselves, their parents and teachers assessed the level of behavioral changes associated with the condition and difficult behavior. In the experimental group, the assessment of behavioral changes reached a maximum of 4.028 on a 5-point scale of positive changes, while the other two groups lagged significantly (2.402 for the support group and 2.12 for the control group). The practical significance of the study lies in the possibility of effective implementation of a support system for adolescents at school based on existing mobile devices and instant messengers without significant costs.

\section{Acknowledgment}

The article is based on research findings obtained within the project of the Ministry of Education and Science of the Republic of Kazakhstan "Scientific Theoretical Fundamentals and Prevention of Suicide among Youth”.

\section{$7 \quad$ References}

[1] Das, J.K., Salam, R.A., Arshad, A., Finkelstein, Y., Bhutta, Z.A. (2016). Interventions for adolescent substance abuse: An overview of systematic reviews. Journal of Adolescent Health, 59(4): S61-S75. https://doi.org/10.1016/j.jadohealth.2016.06.021 
[2] Koch, I.A., Orlov, B.A. (2020). Values and professional identity of student-age population. The Education and science journal, 22(2):143-170. (In Russian).

[3] Feng, L., Lan, X. (2020). The moderating role of autonomy support profiles in the association between grit and externalizing problem behavior among family-bereaved adolescents. Frontiers in Psychology, 11: 1578. https://doi.org/10.3389/fpsyg.2020.01578

[4] Muratori, P., Lochman, J.E., Bertacchi, I., Giuli, C., Guarguagli, E., Pisano, S., Gallani, A., \& Mammarella, I.C. (2019). Universal Coping Power for pre-schoolers: Effects on children's behavioral difficulties and pre-academic skills. School Psychology International, 40(2): 128-144. https://doi.org/10.1177/0143034318814587

[5] Quach, J.L., Nguyen, C.D., Williams, K.E., Sciberras, E. (2018). Bidirectional associations between child sleep problems and internalizing and externalizing difficulties from preschool to early adolescence. JAMA pediatrics, 172(2): 174363-174363. https://doi.org/10.1001/jamapediatrics.2017.4363

[6] Zinchenko, Y.P., Dorozhkin, E.M., Zeer, E.F. (2020). Psychological and Pedagogical Bases for Determining the Future of Vocational Education: Vectors of Development. The Education and science journal, 22(3): 11-35. (In Russian). https://doi.org/10.17853/19945639-2020-3-11-35

[7] O'Dea, B., Achilles, M.R., Werner-Seidler, A., Batterham, P.J., Calear, A.L., Perry, Y., Shand, F., Christensen, H. (2018). Adolescents' perspectives on a mobile app for relationships: cross-sectional survey. JMIR mHealth and uHealth, 6(3): e56. https://doi.org/10.2196/preprints. 8831

[8] Seah, M.L.C., Koh, K.T. (2020). The efficacy of using mobile applications in changing adolescent girls' physical activity behaviour during weekends. European Physical Education Review, 1: 1356336X20930741. https://doi.org/10.1177/1356336x20930741

[9] Corchado, A.I., Martínez-Arias, R. (2020). Screening of Problem Behavior Syndrome in Adolescents. Child and Adolescent Social Work Journal, 1: 1-11. https://doi.org/10. 1007/s10560-020-00699-9

[10] Papageorgiou, K.A., Likhanov, M., Costantini, G., Tsigeman, E., Zaleshin, M., Budakova, A., Kovas, Y. (2020). Personality, Behavioral strengths and difficulties and performance of adolescents with high achievements in science, literature, art and sports. Personality and Individual Differences, 160: 109917. https://doi.org/10.1016/j.paid.2020.109917

[11] Sharma, P., \& Sharma, N. Nature and kinds of behavioral difficulties prevalent among adolescents. International Journal of Psychology and Education, 3(2): 1-13.

[12] Abeele, M.V., Schouten, A.P., Antheunis, M.L. (2017). Personal, editable, and always accessible: An affordance approach to the relationship between adolescents' mobile messaging behavior and their friendship quality. Journal of Social and Personal Relationships, 34(6): 875-893. https://doi.org/10.1177/0265407516660636

[13] Poulain, T., Vogel, M., Ludwig, J., Grafe, N., Körner, A., Kiess, W. (2019). Reciprocal longitudinal associations between adolescents' media consumption and psychological health. Academic pediatrics, 19(1): 109-117. https://doi.org/10.1016/j.acap.2018.08.009

[14] Seo, D.G., Park, Y., Kim, M.K., Park, J. (2016). Mobile phone dependency and its impacts on adolescents' social and academic behaviors. Computers in human behavior, 63: 282292. https://doi.org/10.1016/i.chb.2016.05.026

[15] Badawy, S.M., Barrera, L., Sinno, M.G., Kaviany, S., O’Dwyer, L.C., Kuhns, L. M. (2017). Text messaging and mobile phone apps as interventions to improve adherence in adolescents with chronic health conditions: a systematic review. JMIR mHealth and uHealth, 5(5): e66. https://doi.org/10.2196/mhealth.7798 
[16] Ippoliti, N.B., L'Engle, K. (2017). Meet us on the phone: mobile phone programs for adolescent sexual and reproductive health in low-to-middle income countries. Reproductive health, 14(1): 11. https://doi.org/10.1186/s12978-016-0276-z

[17] O’Dea, B., Han, J., Batterham, P.J., Achilles, M.R., Calear, A.L., Werner-Seidler, A., Parker, B., Shand, F., Christensen, H. (2020). A randomised controlled trial of a relationship-focussed mobile phone application for improving adolescents' mental health. Journal of Child Psychology and Psychiatry, 61(8): 899-913. https://doi.org/10.1111/jcpp.13294

[18] Chen, R., Liu, J., Cao, X., Duan, S., Wen, S., Zhang, S., Xu, J., Lin, L., Wue, Z., Lu, J. (2020). The relationship between mobile phone use and suicide-related behaviours among adolescents: the mediating role of depression and interpersonal problems. Journal of affective disorders, 269: 101-107. https://doi.org/10.1016/j.jad.2020.01.128

[19] Morese, R., Palermo, S., Defedele, M., Nervo, J., Borraccino, A. (2019). Vulnerability and social exclusion: risk in adolescence and old age. In The New Forms of Social Exclusion and Social Inclusion. Intech, pp. 1-16. https://doi.org/10.5772/intechopen.85463

[20] Choi, K.S., Lee, S.S., Lee, J.R. (2017). Mobile phone technology and online sexual harassment among juveniles in South Korea: Effects of self-control and social learning. International Journal of Cyber Criminology, 11(1): 110-127.

[21] Mimbi Dr, L., Nembandona, P., Mtshazi, S. (2018). Mobile bullying among rural South African students: Examining the applicability of existing theories. The African Journal of Information Systems, 10(2): 1.

[22] Sánchez-García, M.D.L.Á., Lucas-Molina, B., Fonseca-Pedrero, E., Pérez-Albéniz, A., Paino, M. (2018). Emotional and behavioral difficulties in adolescence: Relationship with emotional well-being, affect, and academic performance. Annals of psychology, 34(3): 482-489.

[23] Iotti, N.O., Thornberg, R., Longobardi, C., Jungert, T. (2020). Early Adolescents' Emotional and Behavioral Difficulties, Student-Teacher Relationships, and Motivation to Defend in Bullying Incidents. In Child \& Youth Care Forum. Springer US, Vol. 49, No. 1, pp. 59-75. https://doi.org/10.1007/s10566-019-09519-3

[24] Kosse, R.C., Bouvy, M.L., Belitser, S.V., De Vries, T.W., Van Der Wal, P.S., Koster, E.S. (2019). Effective Engagement of Adolescent Asthma Patients with Mobile HealthSupporting Medication Adherence. JMIR mHealth and uHealth, 7(3): e12411. https://doi. org/10.2196/preprints.12411

[25] Badawy, S.M., Kuhns, L.M. (2017). Texting and mobile phone app interventions for improving adherence to preventive behavior in adolescents: a systematic review. JMIR mHealth and uHealth, 5(4): e50. https://doi.org/10.2196/mhealth.6837

[26] Maor, D., Mitchem, K. (2020). Hospitalized adolescents' use of mobile technologies for learning, communication, and Well-being. Journal of Adolescent Research, 35(2): 225247. https://doi.org/10.1177/0743558417753953

[27] Niu, G., Yao, L., Wu, L., Tian, Y., Xu, L., Sun, X. (2020). Parental phubbing and adolescent problematic mobile phone use: The role of parent-child relationship and selfcontrol. Children and Youth Services Review, 116: 105247. https://doi.org/10.1016/j.childyouth.2020.105247

[28] Zhen, R., Liu, R.D., Hong, W., Zhou, X. (2019). How do interpersonal relationships relieve adolescents' problematic mobile phone use? The roles of loneliness and motivation to use mobile phones. International journal of environmental research and public health, 16(13): 2286. https://doi.org/10.3390/ijerph16132286 
[29] Gindidis, S., Stewart, S., Roodenburg, J. (2019). A systematic scoping review of adolescent mental health treatment using mobile apps. Advances in Mental Health, 17(2): 161-177. https://doi.org/10.1080/18387357.2018.1523680

[30] Grist, R., Porter, J., Stallard, P. (2017). Mental health mobile apps for preadolescents and adolescents: a systematic review. Journal of medical internet research, 19(5): e176. https:// doi.org/10.2196/jmir.7332

[31] Holyfield, C., Caron, J.G., Drager, K., Light, J. (2019). Effect of mobile technology featuring visual scene displays and just-in-time programming on communication turns by preadolescent and adolescent beginning communicators. International journal of speechlanguage pathology, 21(2): 201-211. https://doi.org/10.1080/17549507.2018.1441440

\section{Authors}

Kassen Gulmira is a $\mathrm{PhD}$ of Pedagogical Science, Associate Professor, Department of Educational and Pedagogical Management, Kazakh National University Al-Farabi, Almaty, Kazakhstan.

Kudaibergenova Aliya is a $\mathrm{PhD}$ of Pedagogical Science, Associate Professor, Department of Educational and Pedagogical Management, Kazakh National University Al-Farabi, Almaty, Kazakhstan.

Mukasheva Anar is a $\mathrm{PhD}$ of Pedagogical Science, Associate Professor, Department of Educational and Pedagogical Management, Kazakh National University Al-Farabi, Almaty, Kazakhstan.

Yertargynkyzy Dinara is a $\mathrm{PhD}$ of Pedagogical Science, Senior Lecturer, Department of Educational and Pedagogical Management, Kazakh National University Al-Farabi, Almaty, Kazakhstan.

Moldassan Kuanysh is a $\mathrm{PhD}$ of Pedagogical Science, Associate Professor, Department of Educational and Pedagogical Management, Kazakh National University Al-Farabi, Almaty, Kazakhstan.

Article submitted 2020-09-15. Resubmitted 2020-11-06. Final acceptance 2020-11-08. Final version published as submitted by the authors. 